\title{
A collaborative game-based learning to enhance ecological economics teaching
}

\begin{abstract}
David Hoyos ${ }^{1,2}$, Waleska Sigüenza ${ }^{3}$, Iñigo Capellán-Pérez ${ }^{4}$, Álvaro Campos ${ }^{5,3}$, David Álvarez-Antelo ${ }^{4}$

${ }^{1}$ Department of Applied Economics III (Econometrics and Statistics), Faculty of Economics and Business, University of the Basque Country (UPV/EHU), Spain. ${ }^{2}$ EKOPOL, Research Group on Ecological Economics and Political Ecology, Spain. ${ }^{3}$ Department of Applied Economics II (Public Finances and Tax Law), Faculty of Economics and Business, University of the Basque Country (UPV/EHU), Spain. ${ }^{4}$ Research Group on Energy, Economy and System Dynamics, University of Valladolid, Spain. ${ }^{5}$ Department of Thermal Machines and Motors, Faculty of Engineering, University of the Basque Country (UPV/EHU), Spain.
\end{abstract}

\begin{abstract}
Game-based learning refers to the use of game thinking and mechanics to engage and motivate students in the learning process. We applied this innovative concept to complement the theoretical sessions of an introductory course on ecological economics in the Faculty of Economics and Business of the University of the Basque Country (UPV/EHU). A participatory simulation game originally developed by Capellán-Pérez et al. (2019) in the context of energy and sustainability education was adapted for this course and, at the same time, the theoretical sessions were reshaped to enhance the learning experience of the gaming. The pedagogical effect of the course innovation was evaluated with a previous and posterior questionnaire. The results show that this combined strategy is especially suited to motivate and engage students into the discipline of ecological economics, as well as in order to promote team work and collaborative thinking. We also observed that students gained a better global vision and understanding of the interrelation between the topics discussed during the course and a greater capacity to interiorise the global socio-environmental crisis that humanity is currently facing.
\end{abstract}

Keywords: Game-based learning; Ecological economics. 


\section{Introduction}

Scientific research is increasingly showing that the current socioeconomic system is leading the world towards overshoot and collapse (Rockström et al., 2009; Steffen et al., 2015). Urgent and radical global control measures are needed in order to avoid catastrophic consequences of global warming and the surpass of other planetary boundaries (McGlade and Ekins, 2015; Randers, 2012).

Transiting into a sustainable economic system is a global challenge requiring a substantial change of behaviour and values (especially in increasingly materialised western societies) in order to rescale needs and desires under the limits of the availability of natural resources and ecosystem services. The effectiveness of sustainable policy measures require active collaboration between individuals, regions and political institutions among the world, which emphasises the need to facilitate participants of the course with a deep understanding both of the severity of the problem as well as the complexity of the solutions. In fact, teaching about ecological economics and sustainability is not an easy task given the cognitive difficulties that humans have in understanding the functioning of complex systems.

Faculties of Economics and Business present nowadays a general lack of criticism to the neoclassical paradigm that sustains the current economic system (e.g. the growth imperative), and therefore, very little room is left for alternative approaches like that of ecological economics. In this context, the annual Course on Ecological Economics at the Faculty of Economics and Business of the University of the Basque Country (30-40 students per annum) started as an attempt to include these concepts in the study program. The course was initially conceived as a research-based learning introductory course of 20 hours through an integral learning process for undergraduates, postgraduates and academic staff of any discipline.

In its fifth edition (2018), a gamification strategy was incorporated into the learning process adapting the participatory simulation game Crossroads-World developed by the Group of Energy, Economy and System Dynamics of the University of Valladolid in the context of energy and sustainability education. The game is based on the MEDEAS-World model, a global, state-of-the-art, one-region energy-economy-environment model (or integrated assessment model) designed applying System Dynamics (Capellán-Pérez et al., 2017). System Dynamics has proved to be a particularly well adapted modelling methodology for gamification (Alessi and Kopainsky, 2015).

The aims of this hybrid strategy combining theoretical sessions with gamification were: (1) to provide students with better comprehension of the magnitude and potential consequences of the global environmental crisis; (2) to promote collective reflexive thinking on the topics of the course; (3) to acknowledge the importance of access and critical evaluation of 
information and its sources; (4) to implement a multidisciplinary thinking to better understand and interiorise the link between the newly acquired knowledge and the challenges facing in their own lives; and (5) to provide knowledge to assist participants to actively invent and apply solutions in their personal and collective life.

The use of a participatory simulation game was motivated by the need to enhance students' motivation and participation through the experience acquired in practical scenarios with upto-date scientific methods and data. The game-based learning (GBL) approach also aimed to reinforce their motivation to search imaginative solutions to the environmental problems facing our planet.

\section{GBL METHODOLOGY}

\subsection{Course design}

The gaming strategy by means of the Crossroad-World simulation game aimed to promote the active participation of students in the learning process as well as a reflective evaluation of their decision process by successively running the model. The main objetives of the game were twofold (Capellán-Pérez et al., 2019): (1) raising awareness on the severity of the global environmental crisis that humans are facing, and (2) understanding that different approaches may be taken to deal with this issues based on different ethic or ideological standpoints. The game ultimately allowed students to interiorise that our needs (or desires) are limited by biophysical constraints. Consequently, Crossroad-World simulation game was chosen as the backbone of the research-based learning course on ecological economics given its scientific up-to-date state-of-the-art, and being developed consistently with Ecological Economics’ main principles.

In order to have a successful adaptation process between the game potential and the objectives of the course, it was necessary to start by defining the pre-requisites and starting conditions for the game. The idea was to lay the groundwork to adapt the game to the topics of the course and, at the same time, adapt the learning activities to the requirements of the game. This way, students could engage and settle the topics discussed in the teaching sessions and relate them to the challenges that climate change and depletion of natural resources represent to human societies which they experience during the game. All these needs were put in common in a workshop among all teachers before the course. The next step was to adapt and simplify the participatory simulation game to the requirements of the introductory course on ecological economics (i.e. modifiable options of the game such as a policy to modify the economic structure through dynamic evolution of the input-output matrix, interface adaptation, group dynamics design, etc.). As mentioned before, the gamification strategy was incorporated transversely to all the topics in the course, so it was also necessary to adapt and develop teaching material based on the requirements of the 
simulation game. Specific activities were designed to introduce some specific topics as demanded by the participatory simulation game. These activities were developed in coordination between the teaching staff and the developers of the simulation game following a common structure and nomenclature. In addition to an introductory session presenting the course and the gamification strategy, all the theoretical sessions were oriented to provide with specific inputs to the simulation game that would run in the last session of the course. Table 1 presents the topics covered by the different theoretical sessions of the course.

Table 1. Description of the theoretical sessions of the course on ecological economics.

\begin{tabular}{cccc}
\hline Day & Duration & Topic & Code \\
\hline 1 & 70 mins & Transition towards a sustainable economy & M1 \\
& 70 mins & Evaluation of the ecosistemic services & M2 \\
& 70 mins & Main challenges of climate change & M3 \\
& 70 mins & Waste management and transport & M4 \\
2 & 70 mins & Economy and ecological debt & M5 \\
& 70 mins & Sustainable energy transition & M6 \\
\hline
\end{tabular}

\subsection{Gaming session}

The gaming strategy was organised on a cooperative team-learning process, following the Student Team Learning methodology (Devries and Edwards, 1973). The learning activity was carried out in a final one session by heterogeneous teams searching cooperative learning within groups (among peers). The objective was to compare and discuss in group the level of achievement of the goals of the simulation game among different teams. A facilitator per group helped participants solving their doubts and working with the Crossroads-World graphical interface.

The horizon of the simulations was set in the mid-century (2050-80) following the EU Energy Roadmap (European Commission, 2011) and the IPCC recommendations (IPCC, 2014)). The first step was the constitution of groups. In our case, it was 5 groups with 4-5 members. Once the groups were constituted, participants were invited to select the key hypotheses. Hypotheses are two assumptions (not affected by human decisions) that the simulation game requires as starting point: (H1) future availability of non-renewable energy resources (namely, oil, gas, coal and uranium); and (H2) future climate change impacts.

The third step was to perform a simulation of the extrapolation of current trends as perceived by the participants. The main purpose of this step was to visualize where current 
trends could lead us by 2050-2080. In the light of the results obtained, participants could collectively decide to set some desirable targets in terms of an environmental objective (i.e. global average temperature stabilisation, O1) a welfare objective (i.e. using future availability of energy per capita, O2). Objectives could be changed during the game.

Consequently, in the next step, participants started to build alternative scenarios that iteratively allows them to understand the dynamics of complex systems and the ethical dilemmas behind different choices. The first scenario extrapolating current trends serves as basis for comparison of the alternative simulations. To do so, they could define a set of 12 policy targets: (1) Population growth, P1; (2) Planned growth of GDP per capita, P2; (3) evolution of the structure of the world economy, P3; (4) Implementation of a reforestation program to capture CO2, P4; (5) Planned nuclear power capacity, P5; (6) Planned liquid biofuels production, P6; (7) Planned renewable energy capacity for electricy production, P7; (8) Planned renewable energy capacity for heat production, P8; (9) transport system structure, P9; (10) Planned technological change, P10; (11) minerals recycling rate; and (12) evolution of other GHG emissions apart from burning fossil fuels, P12. As previously mentioned, the contextualisation and definition of these hypothesis $(\mathrm{H})$, objectives $(\mathrm{O})$ and policies $(\mathrm{P})$ were covered by the theoretical sessions as presented in Table 2.

Table 2. Relation between sessions and the hypothesis, objectives and policies covered.

\begin{tabular}{llccc}
\hline \multicolumn{1}{c}{ Topic } & Code & Hypothesis & Objectives & Policies \\
\hline Transition towards a sustainable economy & M1 & & & P2, P10 \\
Evaluation of the ecosistemic services & M2 & & O1 & P4, P6 \\
Main challenges of climate change & M3 & H2 & & P9, P11 \\
Waste management and transport & M4 & & & P1, P3 \\
Economy and ecological debt & M5 & & O2 & P5, P6, P7, P8 \\
Sustainable energy transition & M6 & H1 & & \\
\hline
\end{tabular}

The final step was a group discussion including all participants from all groups and debriefing of the alternatives simulated by different groups. At this point, each group briefly presented their results, reflections and comments of the simulations that they had run. Finally, a general discussion among participants took place with the assistance of the facilitators. This final step aimed to connect the gaming experience of the participants with the topics discussed during the course. The ultimate purpose of the game (and the system dynamics model behind the game) was to provide participants in the course with strategic planning policy orientations and the ethical dilemmas arising from the evaluation of their feasibility or acceptability. 


\section{Monitoring and evaluation}

In order to assess the monitoring and evaluation of the GBL process, two surveys were developed, one to be passed before the course and the other, right after the game session. Several of the questions appeared in both surveys. Each student was asked to fill each survey with a personal and anonymous code to allow cross-checking and, therefore, comparative analysis of the answers before and after the course.

The first survey consisted of 14 questions, organized in three sections. First, a battery of questions is presented to gather personal information and general opinions on economic related issues. Subsequently, a set of questions on climate change and international climatic policies are presented. The survey ends with some questions on the learning methodology itself. The second questionnaire was also divided into 3 sections, including additional 14 questions in total. In this case, the first section gathers information on the satisfaction level of the students and the eventual influence of the course on them. The second and third sections, maintain the same contents of the initial survey, with identical questions for comparison purposes and others that complement them. For those questions in the survey to be answered by an evaluation scale, a Likert-alike evaluation method was used, with a mark range between a minimum of 6 and a maximum of 10 .

\section{Results and discussion}

From a pedagogical point of view, we aimed at evaluating the clarity of the objectives of the course, the motivation of the students, the interactions between students, and the personal impacts of the contents of the course. In addition, from the point of view of the contents, it was intended to evaluate mainly the information received (quantity and quality) and the extent to which the information received was adapted to the interest of the participants. The final sample consisted of 19 finished pairs of questionnaires (previous and posterior), with $16 \%$ males and $84 \%$ females, $100 \%$ holding degree in higher education and an average age of 31 years old. It must be noted that, although the course is directed to undergraduates, postgraduates and academics, most participants were postgraduate researches and young academics of non-economics disciplines.

The introductory course on ecological economics is a open course so, unsurprisingly, attendees were generally aware of the current environmental crisis. As shown by the analysis of the previous questionnaire, all students felt that climate change will have mainly negative or very negative effects on human well-being if current trends continue. In a 1 to 10 scale, their average concern about global issues was 9. Regarding the evaluation of the gaming strategy, participants were previously asked whether they had any knowledge about innovative teaching methodologies, in general, and game-based learning strategies, in particular. Nearly $80 \%$ of the students had previously worked in innovative teaching 
environments. All of these students considered that innovative learning methodologies were more motivating and/or influenced their study initiative. However, only $53 \%$ of the participants had heard about game-based learning methodologies. Despite this, $100 \%$ of the participants considered that the use of the simulation game as a teaching methodology was adequate amd that they had understood its purpose and functioning. Similarly, all participants considered that using a game-based learning methodology was more motivating and/or that it had influenced their study initiative. Crossroads-World obtained excellent results when participants were asked to rate in a 1 to 10 scale if the game had been; understandable (7.90), entertaining (8.74), useful in terms of learning (8.95) and rigorous and objective (8.17).

In the same line of positive evaluations, there is a general agreement that game-based learning facilitates mutual support among peers, contributes to create a sense of team, improves the classroom environment, encourages communication and helps to consolidate the knowledge acquired during the course. Finally, the posterior questionnaire showed that the Crossroads-World simulation game fosters participation and involvement in the course and motivates research on the topics discussed. Furthermore, participants clearly stated that the gaming environment had helped them better understanding the problem and its consequences in comparison with more traditional courses.

\section{Conclusions}

This paper provides with an application of a gaming strategy as an innovative learning tool, capable of better motivating and engaging students and, at the same time, proving with autonomous, participatory and collaborative learning. The pedagogical effect of the GBL strategy applied to the introductory course on ecological economics was evaluated with a previous and posterior questionnaires.

The GBL methodology has meaningfully improved the learning experience of participants and the results show that gaming strategies can be specially suited for teaching sustainability issues in higher education contexts by: (1) allowing a better comprehension of the magnitude and consequences of the environmental crisis; (2) promoting the reflexive thinking on the topics of the course; (3) acknowledging the importance of access and critical evaluation of information and its sources; and, above all, (4) implementing a multidisciplinary thinking to better understand and interiorise the link between the newly acquired knowledge and the challenges facing in their own lives. All in all, the experience has been found to be very successful by participants and academic staff, and the GBL methodology will be implemented again as a centrepiece in future editions of the introductory course on ecological economics. 


\section{References}

Admiraal, W., Huizenga, J., Akkerman, S., Dam, G. ten, 2011. The concept of flow in collaborative game-based learning. Computers in Human Behavior, Group Awareness in CSCL Environments 27, 1185-1194. https://doi.org/10.1016/j.chb.2010.12.013

Akkerman, S., Admiraal, W., Huizenga, J., 2009. Storification in History education: A mobile game in and about medieval Amsterdam. Computers and Education 52, 449459. https://doi.org/10.1016/j.compedu.2008.09.014

Alessi, S., Kopainsky, B., 2015. System Dynamics and Simulation/Gaming: Overview. Simulation \& Gaming 46, 223-229. https://doi.org/10.1177/1046878115596390

Capellán-Pérez, I., Álvarez, D., Miguel, L.J., 2019. Crossroads-World: A Participatory Simulation Game to Educate in the Energy and Sustainability Challenges of the 21st Century. The Journal of Science Education and Technology under review.

Capellán-Pérez, I., de Blas, I., Nieto, J., De Castro, C., Miguel, L.J., Mediavilla, M., Carpintero, Ó., Rodrigo, P., Frechoso, F., Cáceres, S., 2017. MEDEAS Model and IOA implementation at global geographical level (Deliverable MEDEAS project, http://www.medeas.eu/deliverables No. D4.1). GEEDS, University of Valladolid.

Devries, D.L., Edwards, K.J., 1973. Learning Games and Student Teams: Their Effects on Classroom Process. American Educational Research Journal 10, 307-318. https://doi.org/10.2307/1161661

Garris, R., Ahlers, R., Driskell, J.E., 2002. Games, motivation, and learning: A research and practice model. Simulation and Gaming 33, 441-467. https://doi.org/10.1177/1046878102238607

Jenkins, H., 2004. Game design as narrative architecture. First Person: New Media As Story, Performance, and Game 118-130.

Malone, T.W., Lepper, M.R., 1987. Making learning fun: A taxonomy of intrinsic motivations for learning. Making Learning Fun: A Taxonomy of Intrinsic Motivations for Learning 223-253.

McGlade, C., Ekins, P., 2015. The geographical distribution of fossil fuels unused when limiting global warming to 2 deg]C. Nature 517, 187-190.

Oliva, H.A., 2016. La gamificación como estrategia metodológica en el contexto educativo universitario. 1 29-47. https://doi.org/10.5377/ryr.v44i0.3563

Randers, J., 2012. 2052: A global forecast for the next forty years. Chelsea Green Publishing, White River Junction, Vt.

Rockström, J. et al., 2009. A safe operating space for humanity. Nature 461, 472-475. https://doi.org/10.1038/461472a

Steffen, W. et al., 2015. Planetary boundaries: Guiding human development on a changing planet. Science 347, 1259855. https://doi.org/10.1126/science.1259855 